\title{
Development of contract management system for network companies under economy digitalization
}

\author{
Olga Voronova ${ }^{1, *}$ \\ ${ }^{1}$ Peter the Great St. Petersburg Polytechnic University, Saint Petersburg, Russian Federation
}

\begin{abstract}
In the context of economy digitalization, special attention is paid to process management by company stakeholders, which cannot be considered without regard to the organization's contract strategy, since a significant part of the business processes are consistently negotiated, concluded and executed, and the management of various groups of contracts is an integral part of the operating business model of network trading companies. This article discusses the main tasks of building an effective contract management system, and provides a typical classification of contracts for network trading companies. In the course of the study, the life cycle of the contract is considered. As a result of the research, the structure of the contract management system for network trading companies is presented.
\end{abstract}

\section{Introduction}

At present, rather difficult economic conditions for conducting commercial activities in the retail sector require all market participants to mobilize their external and internal reserves. In this situation, effective contract management becomes one of the key components of successful business of network trading companies.

It should be noted that in the conditions of digitalization of the economy, special attention of company stakeholders is paid to process management, which can not be considered without regard to the contract strategy of the organization. This is due to the fact that the activities of network trading companies are implemented through the implementation of management, basic and supporting business processes. At the same time, during the implementation of a significant part of business processes, there is a consistent agreement, conclusion and execution of various agreements (contracts). Thus, the contract (agreement) is a documentary form that implements the goals of stakeholders, and the management of various groups of contracts is an integral part of the operating business model of network trading companies[1].

Therefore, currently, network marketing companies pay great attention to the development and implementation of contract strategy, development of the competence of owners of key business processes (holders of contracts), their motivation and responsibility

\footnotetext{
*Corresponding author: ilina.olga@list.ru
} 
for the result, since effective contract management directly affects the quality and timing of obligations the timely settlement of commercial and technical problems and, as a consequence, the commercial performance of the company..

\section{Main tasks in the development of an effective contract management system}

According to the reference model of business processes of FMCG network trading companies, the process of "contract Management" refers to managing business processes [2]. In this case, the contract can be both an input and an output (result) of a certain business process. The managing business process "contract Management" includes basic and auxiliary management tools. Thus as the basic means of control can be considered managerial decisions on optimal utilization of resources and settlement of legal relations of the parties, as auxiliary means of management contracts, personnel, software, etc[2].

Since the contract management system is based on optimizing transaction costs, all company contracts must be concluded in accordance with the requirements of the contract management process. Contract holders (responsible persons) are usually the owners or executors of business processes. This category of specialists should clearly represent the stages of the process, the roles and responsibilities of all participants, as well as be responsible for the process and the result of the work and services performed.

The formation of a contract management system for network trading companies is impossible without developing a contract strategy, since only after determining the contractual structure for the company's areas of activity, types, sequence of conclusion and relationship of individual contracts can the KPI of business processes and their corresponding contracts (the results of these business processes) be calculated, which, in turn, will provide an opportunity to assess the effectiveness of the contract strategy of a network trading company as a whole [3].

The problem of constructing an optimal system of contract management:

- develop clear requirements, policies, and procedures for interacting with suppliers and partners at the corporate level;

- comprehensive legal support for all stages of contract execution in accordance with the stated requirements;

- assessment of compliance of contracts with the requirements of regulations approved by the company's stakeholders;

- implementation of an integrated approach to managing the life cycle of concluded contracts;

- ensuring the need for individual departments (business process executors) to provide the necessary information in a timely manner ;

- avoiding duplication of functions in the contract management process;

- ensuring the protection of information and personal data in accordance with the law.

- reducing costs and improving the company's performance;

- quickly solve problems that arise in the process of merging or acquiring companies with different approaches to contract management. 


\section{Classification of contracts of network trading companies}

Figure 1 shows a typical classification of network trading company contracts.

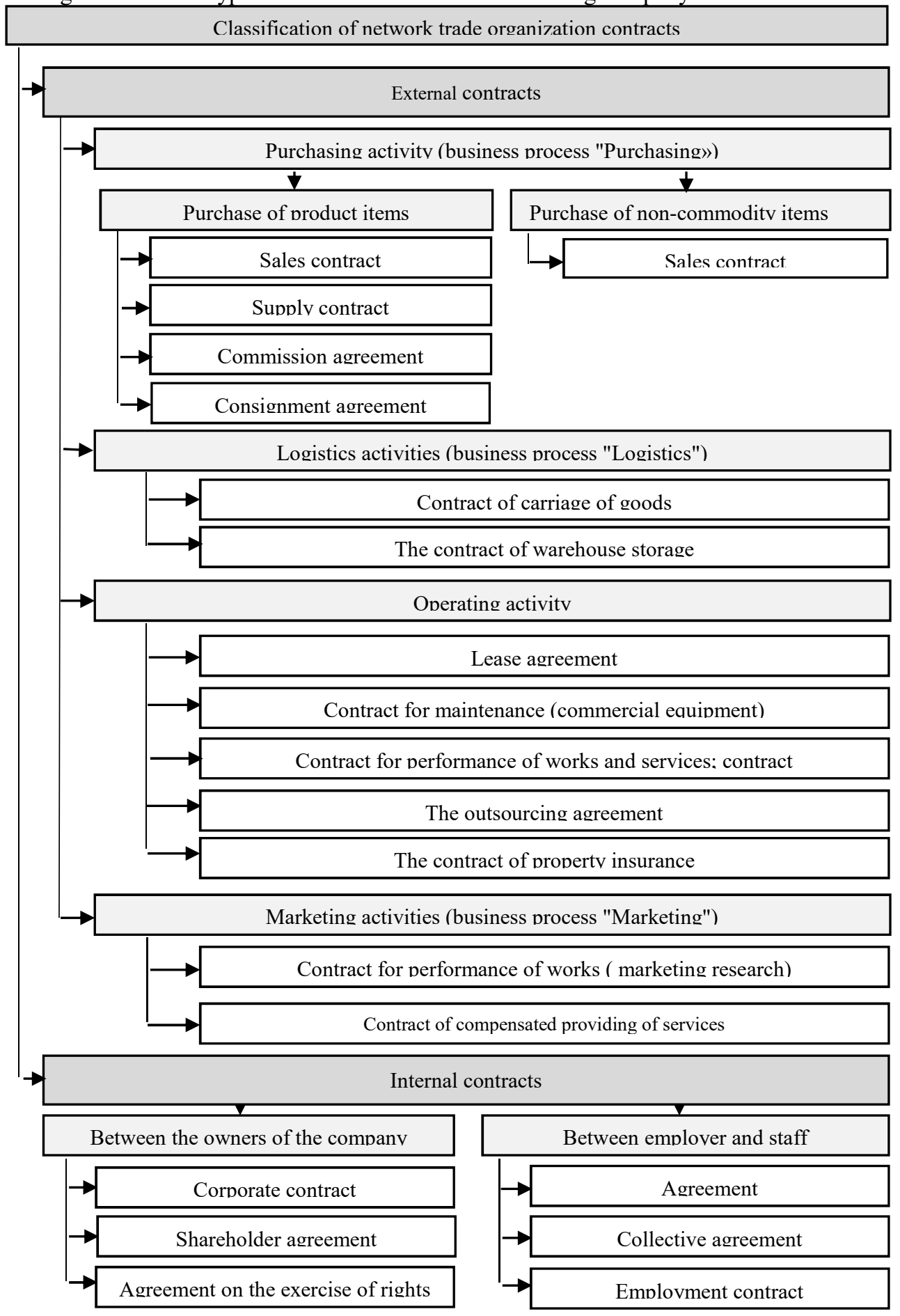

Fig. 1. Classification of contracts of a network trading company by areas of activity. 
Let's consider the classification shown in figure 1 in more detail. From the point of view of the parties involved, it is most appropriate to distinguish internal and external contracts of network trading companies.

In accordance with the contract concept, a company is a set of relations between various economic entities (employees, stakeholders, suppliers, partners, consumers), formalized in the form of various types of explicit and implicit contracts. In this case, the retail sector can be interpreted as a network of external contracts, and a specific network trading company as a network of internal contracts [4].

External contracts are a set of relationships between a network trading company and other market participants, i.e. its contractors (suppliers, partners) and consumers. Taking into account the specifics and variety of network trading companies, it is advisable to subdivide external contracts (contracts) by areas of activity and /or business processes.

It should be noted that linking certain types of contracts to specific business processes allows you to most accurately calculate the effect of each contract individually and the effectiveness of the company's contract strategy as a whole [5].

In accordance with the proposed classification, external contracts of network trading companies are divided into the following areas of activity:

- procurement;

- logistics activity;

- operating activity;

- marketing activity.

As part of the review of external contracts of network trading companies that are classified as purchasing activities, it is necessary to pay special attention to the significant differences in the classification of contracts for the purchase of commodity and noncommodity items.

For example, it should be noted that purchases of non-commodity items in retail do not pay much attention, since expenses for non-commodity materials and services take a small share in the cost price, and management is mainly focused on optimizing purchases of commodity products, in addition, expenses are reflected in different budgets and information systems and they are very difficult to distinguish from the total amount of overhead costs[6]. However, as the network grows and develops, indirect purchasing costs also increase, so reducing indirect purchasing costs by $10-15 \%$ due to effective contract management can have a significant impact on the company's profitability indicators.

As part of the review of external contracts for the logistics activities of network trading companies, it should be noted that transport contracts. Important criteria for carriers when deciding on transportation, in addition to the price, are the nature of the cargo and the requirements for transportation[7]. If the cargo is highly liquid, and the customer puts forward a number of strict requirements and penalties, other things being equal, even with a small difference in price, the carrier will give preference to the simpler option.

The specifics of loading and unloading points are also important, for example, how far they are from the previous and subsequent location; how active the unloading region is; the route - whether the carrier can choose it independently or must follow strict rules; the regularity of working with the customer on the proposed routes, since stability allows the carrier to increase the efficiency of planning.[8]

As part of the review of external contracts of network trading companies that are classified as operating activities, it is necessary to separate the outsourcing contract. This type of contract is quite common in network trading companies, since the removal of narrow-profile divisions from the main business and the transfer of a number of functions to outsourcing allows the company to focus on the strategic direction of the business without diverting time, human and material resources to supporting (additional, accompanying) business processes [9]. Examples of using these processes include the 
following types of outsourcing: full (IT, PR), partial (audit, legal support), periodic (certification).

\begin{tabular}{|c|c|}
\hline \multicolumn{2}{|c|}{ Classification of types of contracts of network companies by a number of features } \\
\hline Classification sign & Type of contract \\
\hline \multirow{2}{*}{$\begin{array}{l}\text { Number of } \\
\text { interested parties } \\
\text { during the contract } \\
\text { settlement period }\end{array}$} & $\begin{array}{l}\text { Mutually agreed agreement - all interested parties participate in } \\
\text { the decision-making process }\end{array}$ \\
\hline & $\begin{array}{l}\text { Accession agreement - all terms of the agreement are set by one } \\
\text { party }\end{array}$ \\
\hline \multirow{2}{*}{$\begin{array}{l}\text { The moment of } \\
\text { emergence of } \\
\text { mutual legal } \\
\text { relations of } \\
\text { interested parties }\end{array}$} & $\begin{array}{l}\text { Consensual agreement-recognized as concluded from the moment } \\
\text { the essential terms of the agreement are agreed upon }\end{array}$ \\
\hline & $\begin{array}{l}\text { Real / present agreement-enters into force from the moment of } \\
\text { transfer of the goods or implementation of other actions stipulated } \\
\text { by the terms of the transaction. }\end{array}$ \\
\hline \multirow{2}{*}{$\begin{array}{l}\text { Degree of } \\
\text { obligation to enter } \\
\text { into a contract }\end{array}$} & $\begin{array}{l}\text { Mandatory contract-is concluded regardless of the parties ' } \\
\text { discretion, the grounds are defined by the civil code of the Russian }\end{array}$ \\
\hline & $\begin{array}{l}\text { Free contract-interested parties can regulate the terms of the } \\
\text { agreement }\end{array}$ \\
\hline \multirow{3}{*}{$\begin{array}{l}\text { Rights and } \\
\text { obligations of } \\
\text { interested parties } \\
\text { to the contract }\end{array}$} & Unilateral agreement \\
\hline & Bilateral treatv \\
\hline & Multilateral treatv \\
\hline \multirow{2}{*}{$\begin{array}{l}\text { By the degree of } \\
\text { compensation for } \\
\text { the provision of } \\
\text { works and services }\end{array}$} & $\begin{array}{l}\text { Gratuitous contract - one party undertakes to provide something } \\
\text { to the other party without receiving a counter-provision. }\end{array}$ \\
\hline & $\begin{array}{l}\text { Paid contract - one party must receive a counter grant for the } \\
\text { performance of its obligations }\end{array}$ \\
\hline
\end{tabular}

Fig. 2. Main types of contracts used by network trading companies.

Internal contracts can be viewed as a set of relationships between stakeholders and staff. These relations are usually regulated by formal contracts [10]. If the legal relationship is not regulated by a formal contract, network companies usually have their own corporate culture and policy of relations between stakeholders and the organization's staff. At the same time, such relationships can be considered as informal contracts, since they are quite stable over a certain period of time.

In turn, internal contracts can be divided into contracts exclusively between business owners and contracts between owners and company personnel. 
As part of the review of internal contracts of network trading companies between owners, it should be noted that a corporate agreement is an agreement between stakeholders (business partners) on the procedure for exercising and exercising their corporate rights.

When considering internal contracts of network trading companies between owners and staff, the most common is an employment contract.

The civil code of the Russian Federation defines many types of civil contracts, each of which has special features and conditions for conclusion.

Figure 2 shows the classification of the main types of contracts by a number of features used by network trading companies [11].

Currently, the contract management system is gradually becoming the basis of the management system of almost any company, since the effectiveness of its financial and economic activities depends on how effectively the contract management system is built in a network trading company [12].

\section{Contract life cycle of network trading companies}

According to the data shown in figure 3, the contract life cycle consists of the following stages:

- preliminary stage;

- preparing a draft contract;

- negotiation phase of the contract;

- execution phase of the contract;

- stage of extantion;

- final stage.

- Currently, the contract management system is gradually becoming the basis of the company's management system.

\section{- 5 Contract management system for network trading companies}

- The contract management system must be integrated with other business applications. Therefore, contract management should not be considered solely as a private task of automating the processing of documents of the same typecontracts[13]. In fact, the task is much broader, since the contract is not only a document that is subject to special accounting, but also the entire system of contractual relations between the customer and the contractor. Any Manager is interested in a complex system that supports all stages of their contract life cycle and gives an overall picture of the state of Affairs, including in relation to the budget, resources, deadlines, etc. [14].

- Figure 3 shows the structure of the company's contract management system for network trading companies. 
The life cycle of the contract

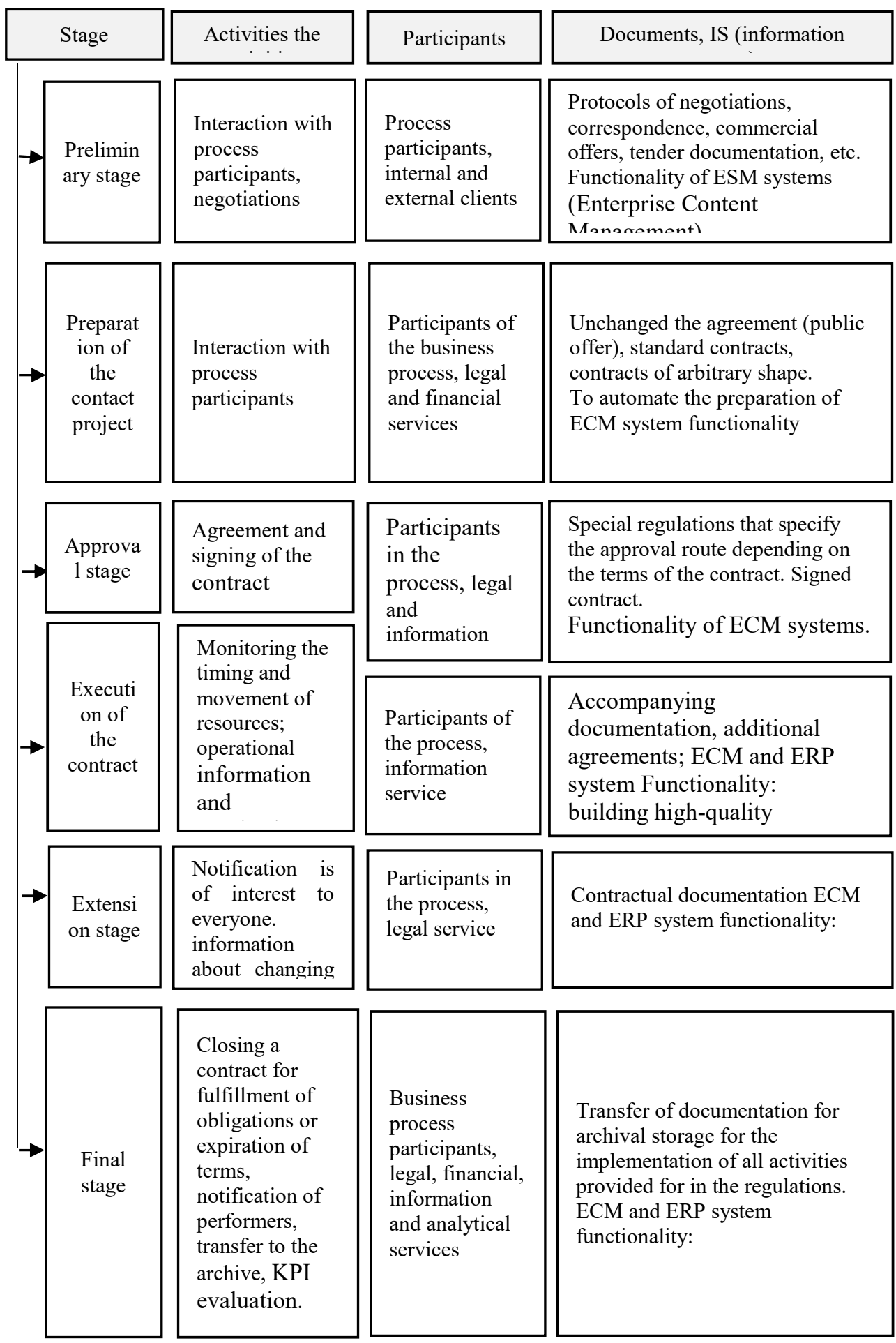

Fig. 3. Life cycle of a network trading company contract. 
Structure of the contract management system

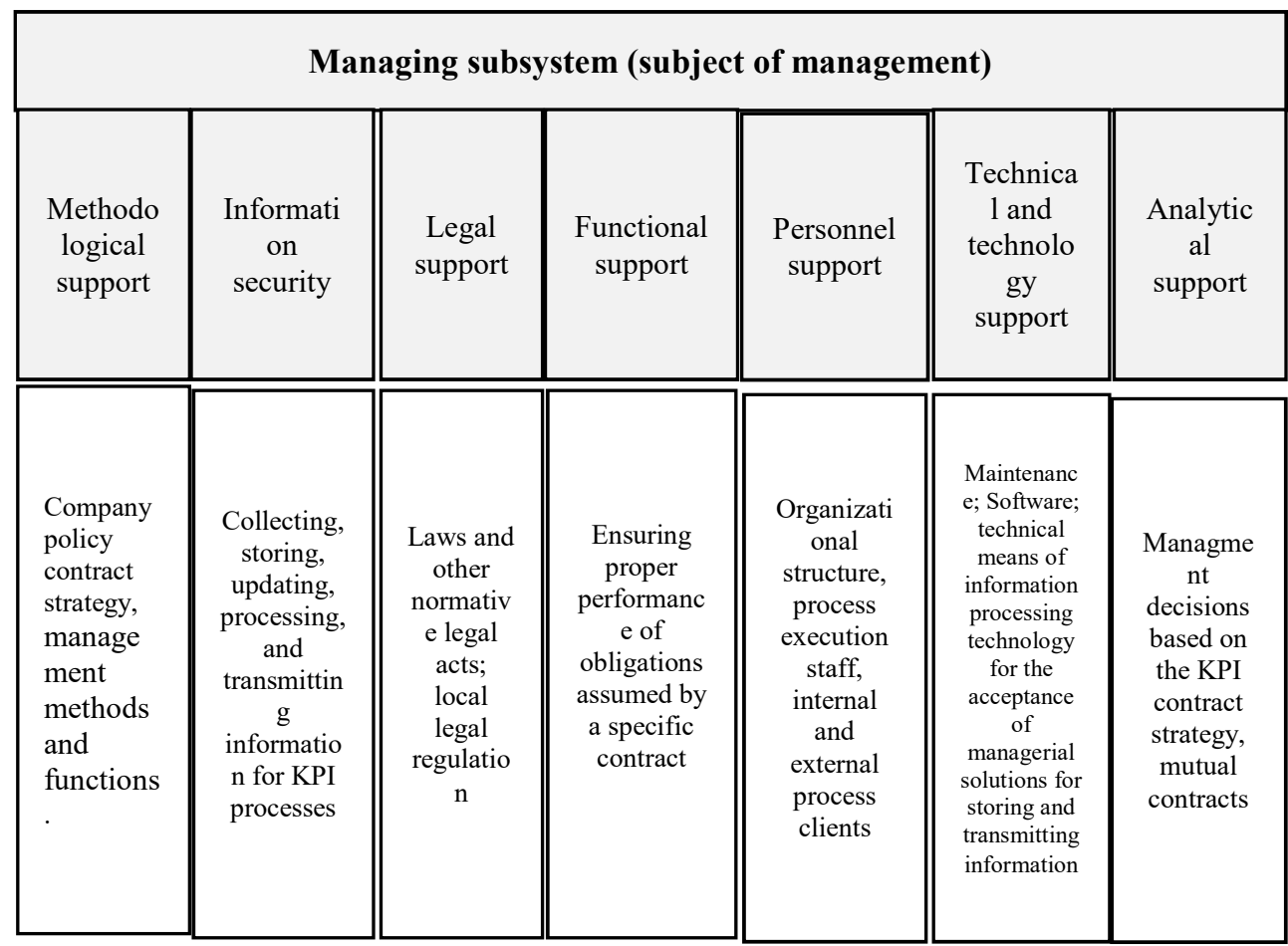

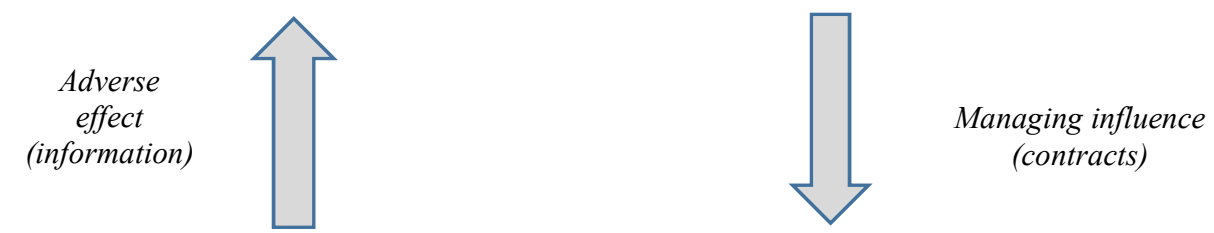

\begin{tabular}{|l|l|}
\hline \multicolumn{2}{|c|}{ Managed subsystem (object of management) } \\
\hline \multicolumn{2}{|c|}{ The resources of the company } \\
\hline \hline
\end{tabular}

Fig. 4. Structure of the contract management system for network trading companies 
It should be noted that the functional support of the enterprise contract management system is always associated with specific areas of activity of the network trade organization and is actually a model for managing a specific contract. At the same time, the composition of functional support for contracts can be very different [15].

Since the contract management system involves many divisions of the company, each of which represents its own interests, it is necessary to take into account the different requirements of individual divisions of the company for automated management systems. In other words, the system must not only meet all the requirements imposed on it by individual divisions of the company involved in the implementation of business processes, but also provide an "end-to-end" business process of the main activity for creating consumer value.

Since in the process of work there is a need for systematization and evaluation of various information (structured and unstructured) in the contract management system, it becomes necessary to use the functionality of systems of different classes (CRM, ECM, ERP, etc.).

Let's consider the main approaches to automating the contract management system of network trading companies that are currently used:

- Development of an information system to meet the requirements of a specific network trading company (requires large financial investments, and is rarely used)

- Purchase of a specific software product and / or automated system, which is subsequently refined to meet the requirements of a specific company. This method requires less investment, but can lead to the fact that the capabilities of the management system developed as a result will be limited by the capabilities of the information system initially purchased.

- Integration of several systems (this approach is the most common). The most commonly used combination that allows you to create a single information space is the interaction of ECM and ERP systems.

\section{Conclusions}

In network trading companies with a large number of counterparties, managing the interaction between them becomes a key aspect of contract management. Contracts cannot eliminate the need to develop effective working relationships between the parties involved in the project, which are based on mutual goals, trust and cooperation.

Given the uncertainty of most projects, no contract can cover all issues, meaning there is currently no perfect contract management system. However, the contract management process is aimed at ensuring that the obligations and requirements of the project are met with the highest degree of efficiency.

Building an effective contract management system is a very important and complex task, since the task of managing contracts is at the intersection of the interests of different counterparties, stakeholders, strutkurnyh divisions and automated systems.

Stakeholders of network trading companies need to determine the contract strategy, that is, choose the contractual structure (types, types, sequence of conclusion and relationship of contracts), set the KPI (performance indicators) of the contract, KPI (performance indicators) of business processes and establish the relationship between them. Only if all these conditions are met, it is possible to make a real assessment of the contract strategy of a network trading company. In other words, by improving the efficiency of contract management, network trading companies will be able to improve their efficiency, competitiveness and protect their interests by optimizing and automating their work with them.

\section{References}

1. I. Ilin, O. Voronova, T. Knykina Proceedings of the 33rd International Business Information Management Association Conference, IBIMA 2019: Education Excellence and Innovation Management through Vision 2020,.5112-5121 (2019). 
2. O. V. Voronova, I. V. Ilyin. Economics and management, 5(163), 81-88 (2019).

3. Y. V. Nadtochy, E. N. Klochko, M. V. Danilina, L. K. Gurieva, R. I Bazhenov, V. V. Bakharev, International Review of Management and Marketing 6(1), 33-39 (2016).

4. T. I. Chueva, M. V. Melnichuk, G. F. Ruchkina, O. V. Ilina, S. F. Litvinova, International Journal of Applied Business and Economic Research 15(23), 245-254 (2017).

5. O. Kalinina, O. Valebnikova, Advances in Intelligent Systems and Computing, 692, 1315-1322 (2018).

6. O. Pirogova, M. Makarevich, O. Ilina, V. Ulanov, IOP Conference Series: Materials Science and Engineering, 012129 (2019).

7. A. R. Bril, O. V. Kalinina, I. V. Ilin, Proceedings of the 30th International Business Information Management Association Conference, IBIMA 2017 - Vision 2020: Sustainable Economic development, Innovation Management, and Global Growth, 2972-2980 (2017).

8. R. S. Tanzanian, D. S. Sorguc, Economics and management of innovative technologies 12(87), (2018).

9. I. Krasyuk, Y. Medvedeva, V. Baharev, G. Chargaziya, IOP Conference Series: Materials Science and Engineering, 012124 (2019).

10. P. V. Shingarev, Problems of the national strategy 6(51) (2018).

11. A. S. Belyaeva, O. V. Rusinovich, Financial economics 1, 125-128 (2020).

12. V. A. Chernenko, S. V. Yuriev, Proceedings of the Saint Petersburg state University of Economics 6(120), 12-20 (2019).

13. V. V. Bakharev, S. S. Nekrasov, Practical marketing 2-1 (240-1), 5-10 (2017).

14. I. V. Kapustina, T. A. Pereverzeva, T. V. Stepanova, Bulletin of the National Academy of tourism 2 (46), 32-36 (2018).

15. K. V. Kudryavtseva, Problems of modern economy 2(70), 182-184 (2019). 